\title{
COMMUNICATION CULTURE AND SOCIO-PSYCHOLOGICAL PROFESSIONAL COMPETENCE OF MODERN SCHOOL DIRECTORS
}

\author{
Shonazarov Asror Makhmaisoyevich \\ Senior teacher \\ Samarkand Institute of Economics and Service \\ Uzbekstan
}

\begin{abstract}
Annotation. The scientific article envisages a comprehensive development of communication culture and sociopsychological professional competence of school principals in the management process on the basis of modern approaches.

Аннотация. Научная статья направлена на формирование у руководителей школ культуры общения и широкого спектра социально-психологических и профессиональных компетенций.

Keywords: Modernity, school, principal, communication, socialization, psychological, professional, competence, motive.

Ключевые слова: современность, школа, директор, общение, социализация, психологический, профессиональный, компетентность, мотив.
\end{abstract}

Relevance of the topic: From all kinds of reforms in our country and the motto "New Uzbekistan - a new worldview", as well as the President of the Republic of Uzbekistan on November 6, 2020 higher education institutions "Quality and education in secondary schools" In order to ensure the implementation of the Decree No. 6108 and Resolution No. 4884 "On improving the professional skills and methodological support of teachers", to show school principals as a personal example to teachers and students, their communication further development of the culture, ensuring the achievement of modern professional competence that leads to the effectiveness of the management process, the implementation of the results of the development of new approaches, proposals, recommendations and guidelines for the activities of managers.

The purpose of the research is to further develop the culture of communication of school principals on the basis of national values and to build their socio-psychological professional competence by modernizing the activities of school principals, to address problems and shortcomings in the management process.

The main objectives of the study: to increase the personal responsibility and accountability of leaders of the general education system, the introduction of incentives that have a positive impact on the effectiveness of the educational process, the involvement of modern innovative technologies in the educational process, broad-minded high competence formation of a reserve of leaders, training of leading personnel for the improvement of education and science of the country, raising the prestige and discipline of teachers in our society, regular training of active and dedicated teachers in the community to strengthen, to treat students with respect to teachers, to educate students in the spirit of creativity, to create opportunities for young people interested in scientific and creative activities in the general education system, to work in a team. Forming an environment of mutual respect, team building knowledge, skills, competencies and professional skills y Ensuring regular increase, taking into account the specifics of the soup, expanding the participation of the private sector in the education system.

Based on the above objectives, the objectives of the study were identified:

a) Adapting the culture of communication to modern requirements through the formation of socio-psychological professional competence in school principals;

b) The formation of social relations, social consciousness, social outlook and modern image through the formation of new relationships in the minds of school principals;

c) Develop a creative adaptation and a serious approach to their work;

g) Training in the application of non-standard solutions and development techniques in order to be effective;

d) Directing the use of effective control methods to regulate community activities;

e) Be able to use improved options for keeping distance between teacher and students, and $b$.

Based on the above, it should be noted that at the same time to increase the efficiency of management of the general education system, to establish modern management, effective use of existing management opportunities in the country and modern competent management staff. In the future, the comprehensive and rapid development of education, which is the basis of the general education system, will allow schools to operate effectively.

Further development of the education system in the country, improving the quality and efficiency of science, the formation of modern knowledge, skills and competencies of the leaders of the general education system, close cooperation and integration between the education system and science, systematic work is being done to ensure the continuity and continuity of education.

Based on the above, it should be noted that the development of a culture of communication and socio-psychological professional competence of the leaders of the general education system is the basis for the modernization of their activities.

Because the interests of the state and society are achieved through the correct and effective management of the education sector by competent leaders. 
This begs the question. What is a communication process? In what sense is behavior used? What is morality? What does the concept of professional competence mean? What is the meaning of the word profession?

At the heart of the research topic, every management process seems easy at first glance. In fact, the management process in the system of social relations requires from the manager a serious and complex professional-psychological approach, the ability to communicate correctly and appropriately, a high level of competence. Therefore, the above questions are covered in terms of content and substance.

Communication is an Arabic word meaning "to see, meet, receive." That is why communication is a human process. In the process of different activities, people want to say something to each other. Communication is a multifaceted process of developing connections between people based on the need for interaction. Communication involves the exchange of information between co-workers.

In the textbook "Social Psychology" V.M.Karimova, one of the leading scientists in the field of psychology in our country, talks about communication, which is a necessity for the management process and the basis of social relations. ${ }^{1}$ "One of the most important tasks of communication is its participation in social behavior and its coordination. Because the direct purpose and essence of social behavior is to influence people, scientists are focusing on its direction and importance in society". At the same time, when it comes to the above-mentioned forms of social behavior, among them the forms of behavior that determine the place of the individual in society, his prestige and destiny among people are becoming increasingly important. For example:

$>$ Qualities that show kindness and kindness, friendship or enmity between people;

$>$ Factors to achieve a specific goal or to secure power;

$>$ Behavior of the person in cases of self-confidence (assertiveness) or depression (helplessness).

Among the social forms of human behavior associated with kindness and compassion, altruism, that is, the tendency to give generously to others, is becoming one of the most important values of our century.

Research has shown that the process of interpersonal communication, which at first glance may seem easy in human society, is in fact very complex, determined by the acquisition of skills, abilities and experiences necessary for a person to learn and live throughout his life.

Scientific research and analytical studies show that in the management of a modern education system, communication is psychologically important in the system of interactions, how complex it is and is a key tool for the exchange of information. "Communication is such a multifaceted phenomenon and process in the system of social relations that I recommend to include the following at the same time:

1) The process of positive or negative interpersonal interaction;

2) The process of exchanging information and data between people;

3) The process by which individuals interact with each other;

4) The process of influencing one's self and others;

5) The process by which individuals feel and understand each other (empathy);

6) The process of influencing the professional relationship between managers and pedagogical staff.

In the process of governance, communication is seen as the main means of influencing all aspects of the relationship, as well as revealing the true nature of social life.

Based on the above, it is appropriate to distinguish between general concepts such as behavior and ethics in social activities.

Behavior is a concept that is formed by a person living in a society, it is a manifestation of social consciousness, which is reflected in a person's behavior, ethics, attitudes, memory, thinking.

Morality is a set of principles of behavior in human society, community, family.

Leadership ethics differs from the rules of law that govern governance and is based on public opinion, decisions and decrees, the influence of employees, beliefs, traditions and values, customs, and one's own behavior. To work on the basis of readiness to manage, kindness and courtesy, cultural relations with colleagues at work, observance of labor, production, financial discipline.

In the process of moral management, a person is able to behave in difficult situations, to be civilized, to be polite when giving tasks to subordinates, to be considerate of subordinates, to reward their success in a timely manner. Finds the expression $\mathrm{z}$.

As we highlight the concepts of competence and professionalism required for the management process, they are interpreted as follows. ${ }^{2}$

"Competence" is used in the sense of effective use of theoretical knowledge in practice, the ability to demonstrate a high level of professionalism, skills, abilities and talents. To date, many types of competencies have been researched by domestic and foreign scientists and researchers.

Profession - (Latin: "profession" - a formal occupation, specialty) - is a type of activity of experienced individuals with a special set of theoretical and practical skills. In this sense, a profession requires a person's work activity, type of

\footnotetext{
${ }^{1}$ V.M.Karimova. "Social Psychology" - T .: "Science and Technology" Publishing House, 2012, 59 pages.

2 ."National Encyclopedia of Uzbekistan" - T .: "National Publishing House of Uzbekistan", Volume One. 2000.
} 
regular employment, a certain type of work, knowledge, skills, experience that allows him to perform competently. Occupations include specialties that are characterized by the narrowest area of work (e.g., teaching, mother tongue teacher, physical education teacher, Russian language teacher, etc.) Occupations are usually the main source of livelihood for an individual. According to statistics, if we look at the history of professions, there were only 500 professions 3,000 years ago. To date, more than 70,000 professions are distinguished on the basis of social development. ${ }^{3}$

Along with professional development, the industries in each period felt the need for their managers.

If we look at the comments of foreign countries in this regard, "Leadership activities require a high level of teaching skills, are formed from the same set of skills and are used in different environments, for example: in teaching a small group. In addition, leadership requires mutual empathy. A set of leadership skills includes: asking effective questions, listening carefully, and answering. Leaders need to be able to express their views, whether their plans are successful or not."4

In today's world, there are many factors that influence the objective and subjective influence of the leaders of the general education system. The more complex and stratified the task of management, the more the task of leadership is to improve management in any task, both interdisciplinary.

As a result, the task of gradually improving the management of the general education system is separated from the task of managing the general education system by competent leaders using modern methods and tools. This task is the tendency of the leader, that is, to coordinate the activities of subordinates in a spiritual way. At the same time, the purpose of the management of the leading teacher-employee is to expand their abilities on the basis of effective and productive mechanisms.

So, inclinations are the forces that are aimed at forcing a managerial activity with a certain force or force, as a result of a certain action, and with a certain degree of determination, honesty to achieve goals. Modern management requires enlightened, broad and deep professionalism, adherence to high ethical standards.

Through enlightenment and morality, the study of people's socio-psychological attitudes, behaviors and their application in the activities of the organization leads to great success.

One of the requirements for a modern leader today is that he uses all the methods of modern psychology that are suitable for him, first of all, about himself, and then about the personality of his subordinates. Have knowledge and information.

That is, in a sense, the leader must be a psychodiagnostic, able to use psychodiagnostic methods in their work. Because it is necessary to know the psychology of others, to know their personal qualities and shortcomings, to behave properly in different situations, just as it is a way of governing them.

First of all, the head of the modern education system must determine how worthy he is of his managerial activity. Before holding the position, he must have the following qualities and qualities:

$>$ The modern leader must be realistic, that is, all his actions must serve the interests of the educational institution he runs;

$>$ How the leader perceives the team, what he thinks about them, to master their knowledge in this regard;

$>$ To be able to manage the activities of others and the team as a whole through conscious action, and, if necessary, to be ready to do what everyone else is doing together. It will take a lot of hard work.

The leader of a modern education system must be able to complete the tasks related to his / her work and create mechanisms that will allow him / her to enjoy and be satisfied with the work done. To do this, he:

* Focus on managerial potential, creativity and ability to focus, focus their energy and will on effective activities;

* To be able to show in front of subordinates that he is always alert and healthy and always fit for work;

* Be able to focus on the control of other employees, without interfering with the negligent work that can be done by other employees;

* Work tirelessly and focus on team literacy;

* Systematically analyze their management processes by having knowledge of management methods related to their system and other types of organizations and enterprises;

* Be able to accurately use the most modern management methods and introduce innovative technologies in the industry.

The above-mentioned circumstances, of course, lead the head of the modern education system to effectively organize his work and achieve success from the very beginning.

Leadership is a professional relationship. Leaders vary in the way they work with learners, depending on tradition, experience, and type of science. The University of East Anglia (2007) states in its guidelines for research leaders: "Leadership is about honesty, fairness, responsibility, respect, approach to tasks, and working independently in

${ }^{3}$.E.Begmatov, A.Madvaliev and others. National Encyclopedia of Uzbekistan - T .: National Publishing House of Uzbekistan, 1997. B.210.

${ }^{4}$.A handbook for teaching and learning in higher education : enhancing academicpractice / [edited by] Heather Fry, Steve Ketteridge, Stephanie Marshall.-3rd ed.p. cm. pp: 367. 
relationships. and working on their interests". Discussion methods that summarize the leader-learner relationship are presented by Taylor and Beasley (2005).

Management is a choice that requires a high level of art and skill, making decisions based on that choice and monitoring its implementation.

The purpose of management is the realization of a common dream, that is, a common desire to achieve a goal. ${ }^{5}$

It is important that the goal is scientifically sound, so:

* Management functions;

* Management methods;

* Management structure;

- Important issues of appointment and selection of staff will be addressed.

In modern management, the potential of the leader must be high. The style of management stems from the individual characteristics of the leader. But there are also objective factors, such as the laws, principles of governance, the general demand for leaders, the socio-psychological (socio-psychological) environment in the community.

In addition, there are a number of psychodiagnostic methods of management, specific methods, the most convenient and reliable of which are on the desk of the leader, as well as in the works of scientists and celebrities directly involved in the proper organization of human activity. Has only a positive effect. The famous works of a number of well-known psychologists and their art of communication with people can help each specialist to organize their work.

According to Rogers, people can be independent as well as loving. Each of us is like a plant, that is, we can grow and develop regardless of the environment. Rogers argues that human development and formation are influenced by three things: sincerity, caring, and caring. ${ }^{6}$

As a manager performs his or her job responsibilities, he or she will need to sincerely consider the consequences of the tasks being performed, whether they have a negative or positive impact on the performance of the employees. That is why it is very important for the management process that the leader understands the content of each decision, does not rush, and has the appropriate conclusions. In this regard, American psychologists claim that when people consciously draw conclusions, the conclusion occurs after the time when the brain prepares for action, that is, when the brain prepares for it before the time to draw conclusions. Some researchers are skeptical of the human reasoning process. ${ }^{7}$ It is often argued that leaders make decisions step by step. The wrong conclusion of the head of the education system can lead to a decrease in the quality of education and upbringing. Another hypothesis function of inference is that the mind is triggered by a subsequent action when the same situation arises.

Research shows that when a manager or professional plans his or her daily activities, he or she wants the results of his or her activities to be effective and materially and spiritually beneficial. Thus, from the beginning of mankind to the present day, every member of human society is motivated by constant activities from birth to the end of his life.

Motive - Latin "movere" - means to move, to motivate, it has three main meanings:

1) Encouragement of activities related to meeting the specific needs of the subject;

2) The force that determines the direction of activity related to the subject of activity;

3) Perceived reason for the person to choose an action or behavior.

So, motive is a psychological concept that determines the conscious and unconscious activity of a person as a motivation, guiding force and cause. Every action, behavior, thinking has certain criteria and motives.

The fact that each person perceives reality, accepts it, and has a certain system of knowledge is explained by social development. At the same time, each person's knowledge, behavior, manners, and other characteristics reveal his or her unique characteristics.

In short, almost all social qualities of a person are formed and developed under the influence of the external social environment. Therefore, goal-oriented education and upbringing, as well as the free choice of the pupil, play a leading role in the formation of human qualities.

In order to further develop the activities of the general education system, the following main directions of modern requirements have been identified for the leaders:

1) As a modern leader to be committed to national values, to be able to effectively organize their activities, to have new approaches to governance;

2) To be an entrepreneur who participates in the development of the country with new ideas, to show himself as a leader who is able to come to the forefront in time and put into practice new methods;

3) Training of a new generation of personnel with high intellectual and spiritual potential with socio-psychological professional competence, the formation of the necessary knowledge, skills and competencies for graduates of educational institutions to become modern professionals.

5.A handbook for teaching and learning in higher education : enhancing academicpractice / [edited by] Heather Fry, Steve Ketteridge, Stephanie Marshall.-3rd ed.p. cm. pp: 369.

${ }^{6}$.David G. Mayers Psychology, (C) 2010 by Worth Publishers. 590-p.

${ }^{7}$.Kelvin Seifert and Rosemary Sutton, Educational Psychology (C) 2009, Second Edition.324-p. 
In general, improving the performance of the leaders of the general education system is tantamount to ensuring the development of the country, while achieving quality education for students will further enhance the future of the nation.

\section{List of used literature:}

1.V.M.Karimova. "Social Psychology" - T.: "Science and Technology" Publishing House, 2012, 59 pages.

2.David G. Mayers Psychology, (C) 2010 by Worth Publishers. 590-p.

3.Kelvin Seifert and Rosemary Sutton, Educational Psychology (C) 2009, Second Edition. 324-p.

4.A handbook for teaching and learning in higher education: enhancing academicpractice / [edited by] Heather Fry, Steve Ketteridge, Stephanie Marshall. - 3 rd ed.p. cm. pp: 367. 